\section{Justicia derechos El largo camino del reconocimiento de la diversidad}

Criminal justice and indigenous rights. The long way of the recognition of diversity

\section{RODRIGO LILLO}

\section{Resumen}

En el contexto de los 15 años $^{1}$ de vigencia de la reforma procesal penal, se formula un análisis de la valoración que el sistema procesal penal

Departamento de Estudios y Proyectos de la Defensoría Naciona Pública, Chile. Correo electrónico: rlillo@dpp.cl

El nuevo Código Procesal Penal, que impuso un sistema procesa penal de carácter acusatorio, se encuentra contenido en la Ley $\mathrm{N}^{\circ}$ 19.696 de diciembre de 2000. El artículo 484 de este cuerpo lega dispuso una entrada en vigencia de carácter progresivo del nuevo sistema, que se inició en la fecha de publicación del Código en las regiones de La Araucanía y Coquimbo, y culminó con la aplicación del nuevo Código en la Región Metropolitana en junio de 2005. ha hecho del reconocimiento de la diversidad. Es decir, si se han respetado los derechos indígenas recogidos en instrumentos internacionales, particularmente sus derechos ante la justicia. El análisis se centra en dos ejes donde se ha producido un debate acerca de los derechos indígenas. Por una parte, se considera la persecución penal de los mapuche que han sido acusados de participar en delitos vinculados con la protesta por el reclamo de sus derechos territoriales. Por otra parte, se considera el reconocimiento del derecho indígena y de sus tradicionales mecanismos de resolución de conflictos. La evaluación es moderadamente optimista, pues si bien existe un largo camino que recorrer en el reconocimiento de los derechos indígenas ante la justicia, existen notables avances en ambos ejes.

Palabras clave: derechos indígenas, derecho consuetudinario, reconocimiento de la diversidad, proceso penal.

\section{Abstract}

In the context of 15 years [1] of effectiveness of the criminal justice reform, an analysis of the assessment that the criminal justice system has made regarding the recognition of diversity is formulated. In other words, we seek to answer whether the indigenous rights considered by international instruments, particularly those that have to do with justice, are respected or not. The analysis focuses on two axes where there has been debate about indigenous rights. First, the prosecution of Mapuche people who have been accused for offenses related to protest for their territorial rights. Second, the recognition of indigenous rights and traditional mechanisms for conflict resolution. Assessment is cautiously optimistic, because although there is still a long 
way to go in recognizing indigenous rights to justice, there are significant advances in both axes.

Key words: indigenous rights, customary law, recognizing diversity, criminal process.

\section{Introducción}

Hace poco más de 10 años atrás, y a propósito de la implementación del sistema acusatorio entre nosotros, me preguntaba por la importancia que podía tener la reforma procesal en la reivindicación de los derechos de los indígenas en Chile (Lillo 2001)². La respuesta evidente parecía ser que ninguna, porque mientras las demandas de derechos de los pueblos indígenas constituían -y constituyenuna demanda de participación política, y a raíz del deseo determinante de hacerse cargo de sus propios asuntos, la reforma procesal penal apenas vino a intentar mejorar la situación de los ciudadanos cuando son imputados de un crimen o delito. En cambio, más pertinente parecía preguntarse por la manera en la que el nuevo sistema procesal penal enfrentaría el respeto y la garantía de los derechos de los indígenas frente a la justicia, cuestión relacionada pero diferente de la pregunta anterior.

\footnotetext{
Este artículo académico se refiere a una discusión que se dio en medio de la implementación de la Reforma Procesal Penal en la Región de La Araucanía, acerca de cómo se relacionaba esta reforma judicial con las reivindicaciones del movimiento mapuche (territorio y libre determinación). Básicamente, en dicho artículo observo que el debate que se produce por la coincidencia temporal de ambas cuestiones (reforma judicial y demandas indígenas) consiste, en verdad, en tres controversias, a saber: en primer lugar, que la reforma procesal se había hecho sin considerar la participación indígena (al menos mapuche); en segundo lugar sobre qué significaba la aplicación del principio de igualdad y no discriminación ante la justicia en una región pluricultural (o plurinacional) como La Araucanía, y; en tercer lugar, que en la implementación de la reforma procesal se había dejado fuera todo el debate sobre el derecho propio (Lillo 2001).
}

En verdad, la distinción se explica porque mientras la discusión a la que aludo (Lillo 2001) se refería al nuevo procedimiento penal, es decir, a la forma como el Estado ejerce su potestad punitiva, lo que sigue siendo una cuestión permanente es el papel del sistema penal $^{3}$ frente a las demandas indígenas. En efecto, mientras la cuestión aparentemente planteada en el debate público al inicio de la reforma se refería a la manera en que el cambio en el procedimiento para investigar y enjuiciar la comisión de un delito podía -o debía- estar influida por las demandas que los mapuche reclamaban de modo más decidido a partir de finales de los 90 (Pairican 2014), mis aprehensiones se referían, más bien, a si el Estado respetaba y/o respetaría los derechos de los indígenas al ejercer el poder de castigar que se le asigna.

Esta inquietud, a su vez, encerraba dos preocupaciones que aludían a derechos individuales y colectivos, respectivamente. En primer término, se encuentra la necesidad de que el sistema judicial no fuera utilizado como contestación a las demandas de los movimientos indígenas, esto es, que a falta

\footnotetext{
Utilizo este término en el sentido que le otorgó la criminología crítica. Este concepto surge como crítica a la dogmática penal que excluía el análisis ideológico que se encuentra detrás del control social. El derecho penal no constituye un sistema estático de normas, sino uno "dinámico de funciones, en el que pueden distinguirse tres mecanismos susceptibles de analizarse separadamente: el de la producción de normas (criminalización primaria); el mecanismo de la aplicación de normas, es decir el proceso penal que comprende la acción de los organismos de averiguación y que culmina con el juicio (criminalización secundaria), y finalmente el mecanismo de la ejecución de la pena o de las medidas de seguridad" (Baratta 1986: 168). Cada uno de estos mecanismos o niveles del sistema, a su vez, depende de diversos actores: legisladores, en el caso del primer nivel teórico, mientras que la aplicación de las normas -en tanto- "está a cargo de dos actores: desde luego los tribunales de justicia -esa es su función específica- pero también la policía" (Mera y Duce 1996: 3).
} 
de una propuesta democratizadora frente a las demandas del movimiento mapuche, se presentara la lucha de las reivindicaciones como un asunto criminal, y se llevara la discusión sobre la validez y la aplicabilidad de los derechos colectivos a los cuarteles policiales y a los estrados de tribunales.

En segundo término, se encuentra la preocupación sobre una de las dimensiones del reconocimiento de la diversidad y de los derechos de los pueblos indígenas basada en el reconocimiento del derecho indígena (o derecho propio), lo que implica intensos cambios institucionales y paradigmáticos en el Estado: pasar de un estado monista, a uno pluralista (Yrigoyen 1999). Aunque ambas cuestiones son sumamente diferentes, porque se refieren a distintos tipos de derechos, a diferentes actores y fenómenos socio-jurídicos, coinciden en que son debates y conflictos sobre derechos que se dan en un mismo escenario jurídico (Sieder 2002).

\section{El sistema penal como respuesta a las demandas indígenas}

Sobre el primer asunto, vale decir, la utilización del sistema penal para responder a las demandas indígenas, la década pasada nos deja un sinnúmero de enseñanzas. $Y$ es que, si bien la represión de los mapuche que reivindican su tierra (territorio) no es nueva entre nosotros, los dispositivos con que dicho sistema comenzaba a contar la convirtieron en un proceso muy eficaz.

En efecto, "la persecución penal de los mapuche no es nueva en la historia. Durante la primera mitad del siglo XX era frecuente en las disputas por tierra y demarcación de deslindes entre los mapuche y terratenientes que la policía realizara operativos en las comunidades, argumentando que el objetivo era terminar con el cuatrerismo" (González, Mera y Lillo 2007: 64). Más tarde, el gobierno de la dictadura militar (1973-1990) implicó para los mapuche el "fin del proceso de Reforma Agraria, lo que significó la pérdida de las tierras recuperadas, así como también que se persiguiera políticamente a quienes habían participado en el proceso. Esta persecución se expresó en ejecuciones, torturas y encarcelamiento para muchos dirigentes mapuche vinculados al proceso de Reforma Agraria" (Mella 2007: 67).

Durante toda la década pasada, persistentemente se retomó la idea del "conflicto mapuche" como un asunto policial y judicial, donde las demandas indígenas fueron vistas como expresiones sólo de grupos radicalizados y extremos que buscaban alterar el orden. En este contexto, el nuevo sistema penal se presentó como un instrumento eficaz para combatir aquel conflicto. Esto involucró que ciertos actores del sistema como la policía, la fiscalía y los jueces, se orientaran especialmente hacia este tipo de "criminalidad", utilizando instrumentos, como la ley antiterrorista, los testigos "sin rostro", el abuso de la prisión preventiva o la rebaja de los estándares condenatorios. Con ello, se mostraba la cara más represiva de una reforma que, en su gestación, se debatió entre las garantías de las personas y la eficacia del sistema (Stippel 2013). Ese doble corazón del sistema procesal penal tuvo allí su primera disputa.

El efecto que produjo este fenómeno fue que abrió un flanco de cuestionamiento al sistema procesal penal desde la perspectiva de los 
derechos humanos, en particular, se evidenció la crítica formulada por organismos extranjeros ${ }^{4}$, instituciones académicas nacionales ${ }^{5}$, y también -por cierto- órganos internacionales de derechos humanos. El resultado de este proceso, ya sabemos, fue una condena contra Chile por violaciones a la Convención Americana de Derechos Humanos ${ }^{6}$. La Corte Interamericana de Derechos Humanos (en adelante, la Corte) estableció que se vulneraron principios vinculados con derechos a la defensa y el principio de legalidad, pero también hizo ver la inconsistencia en la aplicación de la Ley Antiterrorista (en adelante, LAT) en Chile.

La Corte constata que varios órganos y expertos internacionales han afirmado que Chile no ha resuelto de forma efectiva las causas que dan lugar a la protesta social mapuche en las regiones de Bío Bío y La Araucanía (supra párr. 90). Al respecto, Ben Emmerson, Relator Especial sobre la promoción y protección de derechos humanos en la lucha contra el terrorismo sostuvo que cuando el Estado no cumple con las expectativas de solucionar las reivindicaciones territoriales indígenas mapuches permanece latente el riesgo de que las protestas sociales escalen de nivel (párr.182).

Las consecuencias de esta estrategia pública van más allá de los efectos sufridos por los propios denunciantes de este caso. Por una parte, la Corte hace referencia a los efectos colectivos de estas violaciones al señalar que

Informe Indebido Proceso. Los juicios antiterroristas, los tribunales militares y los mapuche en el sur de Chile, Human Rights Watch (2004); Chile: La otra transición chilena. Derechos del Pueblo Mapuche, política penal y protesta social en un estado democrático, Federación Internacional de Derechos Humanos (FIDH) (2006); Informe anual de Derechos Humanos, Amnistía Internacional (2004).

5 Informes anuales de Derechos Humanos de la Universidad Diego Portales (desde el año 2003), y Anuario de la Universidad de Chile (año 2006).

Sentencia de la Corte Interamericana de Derechos Humanos, 29 de mayo de 2014: Norín Catriman y otros v/s Chile. las sentencias condenatorias de mapuche como autores de delitos terroristas- están cargadas de razonamientos que denotan estereotipos, como, por ejemplo:

las acciones que causaron estos delitos demuestran que la forma, métodos y estrategias empleadas, tenían una finalidad dolosa de causar un estado de temor generalizado en la zona. (...) Los ilícitos antes referidos están insertos en un proceso de recuperación de tierras del pueblo mapuche, el que se ha llevado a efecto por vías de hecho, sin observar la institucionalidad vigente. (Considerando $3^{\circ}$, Sentencia del TOP ${ }^{7}$ de Angol, 23 de septiembre de 2003, citado en el fallo de La Corte, párr. 227) ${ }^{8}$.

Por otra parte, la Corte pone atención en la vulneración de los derechos políticos afectados por la acción del Estado chileno, ya que la inhabilitación política de los líderes mapuche condenados afectó también a sus comunidades y a todo el Pueblo Mapuche (párr. 384 y 385). La Corte también da cuenta del efecto intimidante e inhibidor en el ejercicio de la libertad de expresión, que el uso de la LAT contra los mapuches pudo haber producido en éstos (párr. 376).

En definitiva, el proceso descrito por la sentencia de la Corte no tiene que ver solamente con un proceso judicial en que se han vulnerado los estándares vinculados al juicio justo. Se trata de un proceso de criminalización del movimiento mapuche, uno que permite "entender los mecanismos de regulación y subordinación social puestos en acción por el Estado chileno, con el fin de mantener el presupuesto Estado de Derecho democrático y el carácter homogéneo de la nación chilena" (Mella 2007: 187). Estos fenómenos pueden entenderse a

\footnotetext{
Tribunal de Juicio Oral en lo Penal.

8 El subrayado no es original.
} 
partir de algunas perspectivas criminológicas que buscan comprender el rol político y social del sistema penal (Bustos 2007; Garland 1999; Baratta 1986), ya sea como control social propio de una sociedad excluyente (Young 2003), o derechamente como un instrumento para combatir al enemigo (Villegas 2007).

De alguna forma, este proceso de criminalización constituye una manifestación de la transformación del modelo penal a la que hemos asistido los últimos años, desde un modelo de garantías (Diez 2007) -que entre nosotros casi no tuvo vigencia-, hacia un modelo de la seguridad ciudadana, lo que trasunta en un tipo de política criminal. Se trata de un modelo que intenta satisfacer un sentimiento generalizado de inseguridad, el que puede explicarse en base a diversas variables sociales, pero que se intenta enfrentar exclusivamente con el sistema penal, y que ha inspirado a nuestros gobernantes a formular los cambios legales al sistema.

La importancia que ha adquirido la víctima, la presencia del populismo penal, la inflación penal (criminalización y penalización), y la disminución de las garantías de los imputados, son consecuencia de este mismo proceso (Jiménez et al. 2012). Sobre esto, se advierte que la discusión sobre la política criminal gira, exclusivamente, sobre cómo hacer más eficiente al derecho penal (Hassemer 1998), sin llegar a explicitar que esto es, en verdad, una confrontación entre la eficacia del derecho penal y la vigencia del Estado de derecho. En definitiva, esta instrumentalización ha favorecido una política pública superada por el control y la seguridad, cargada de estereotipos y estigmatización, generadora de un contexto que ha justificado la securitización del territorio mapuche, propendiendo a la represión y favoreciendo la expoliación de sus recursos naturales. Con todo, y aunque las consecuencias nefastas del sistema permanecerán en los afectados, la sentencia de la Corte constituye un hito en el reconocimiento institucional de que la persecución criminal estatal de la que fueron objeto algunas organizaciones y líderes mapuche, durante las dos últimas décadas, violaron derechos humanos, lo que debiera alentar al Estado a formular cambios profundos. Los propios tribunales nacionales habían venido advirtiendo esta situación, en un proceso que incluye desde desechar la calificación terrorista del movimiento mapuche y las acciones atribuidas a alguno de sus miembros ${ }^{9}$, hasta el reciente reconocimiento por la Corte Suprema de que el uso de los testigos sin rostro no puede ser indiscriminado y abierto en el sistema acusatorio ${ }^{10}$.

\section{El derecho indígena en el derecho estatal}

\subsection{Derechos de los pueblos indígenas ante la justicia estatal}

Una segunda disputa que se ha dado en el campo del sistema penal tiene que ver con el

Desde el año 2005 ningún mapuche ha sido condenado por delitos terroristas.

10 Aunque la Corte Suprema ha dictado varios fallos donde señala que el uso de testigos sin rostro está permitido en la ley, recientemente ha ratificado la decisión de una Jueza de Garantía de la octava región que señaló que el anonimato sólo se justifica si existe un grave riesgo para la integridad del testigo, y que esto debe probarse por el ministerio público. Esto es así, porque le corresponde al juez ponderar entre el derecho a la integridad personal del testigo y el derecho a un debido proceso del imputado. Todo esto, partiendo de la base que sí se afecta el derecho a la defensa, cuando no es posible poner a prueba la imparcialidad del testigo en un contrainterrogatorio abierto (Sentencia de la Corte Suprema, 5 de agosto de 2014, en causa Rol No 11.297-2014). 
reconocimiento de los derechos de los indígenas ante la justicia. A su vez, esto se relaciona con el reconocimiento de la justicia indígena y el pluralismo legal, esto es, el reconocimiento de "la coexistencia e interacción de diferentes ordenamientos normativos sobre las mismas situaciones sociales en un espacio geo-político determinado" (Lillo 2002: 1). Esto involucra:

[U]na premisa central, a saber, que el derecho no es un monopolio del Estado, (...) en oposición a las teorías monistas que afirman la vigencia de un solo sistema legal en un espacio y tiempo determinado, que diversos "derechos" tienen vigencia social en forma simultánea y conflictiva. En rigor, esta pluralidad es una cualidad estructural de cualquier sociedad porque ninguna está completamente subordinada a una sola fuente productora de derecho (Guevara 2001: 9-10).

Esta relación conflictiva ha sido, en general, de colonización y dominación. No obstante, desde las últimas décadas, y marcado por la fuerza de los movimientos indígenas y las transformaciones de los Estados, un nuevo imperativo se ha planteado como forma de relaciónal interior de los estados plurinacionales: el reconocimiento de la diversidad ${ }^{11}$.

En términos normativos, este principio es recogido tanto en la Declaración de Naciones Unidas de los Derechos de los Pueblos Indígenas (DNUDPI), como en el Convenio 169 de la Organización Internacional del

Ya desde los 70 surge un cuestionamiento a la identificación de los pueblos indígenas como minorías. En los 80 se desarrolla un amplio debate sobre la libre determinación de los Pueblos Indígenas en las Naciones Unidad y en la OIT. En los 90 varios países de Latinoamérica reformaron sus constituciones políticas o ratificaron el Convenio 169 de la OIT, para incorporar en sus ordenamientos jurídicos el reconocimiento de los Pueblos Indígenas y sus derechos colectivos, y a partir de la década pasada, especialmente en los países andinos, se han realizado esfuerzos por establecer una coordinación entre el derecho indígena y el derecho estatal.
Trabajo (OIT) ${ }^{12}$, y deriva del derecho a la libre determinación, del que son titulares los Pueblos Indígenas. En materia de justicia abarca cuatro dimensiones: i) derecho al reconocimiento del derecho propio por el Estado, en la aplicación del derecho (justicia estatal); ii) derecho al reconocimiento de la jurisdicción indígena; iii) derecho a penas alternativas y pertinentes, y; iv) acceso a la justicia estatal.

El Convenio 169 de la OIT recoge estos derechos en los artículos 8, 9 y 10, los que incluyen el deber del Estado de tomar en cuenta el derecho consuetudinario indígena (artículos 8.1 y 9.2). Efectivamente, el tribunal no sólo está autorizado a ponderar la costumbre indígena que ha sido ventilada en el juicio, "sino que tiene un deber constitucional de hacerlo fundado en la norma analizada del Convenio $N^{\circ} 169$ de la OIT en relación con el artículo 5, inciso segundo de la CPR y 6 y 7 de la misma"13 (Meza-Lopehandia 2013: 419) ${ }^{14}$.

Conforme al Convenio 169 de la OIT, además, los pueblos indígenas tienen el derecho a conservar su propio derecho y aplicarlo, bajo sus métodos propios, lo que forma parte de

Siendo el Convenio 169 un tratado internacional de derechos humanos, forma parte del bloque constitucional -o al menosdel ordenamiento jurídico aplicable por el juez y los demás agentes del sistema. En el caso de la DNUDPI, si bien no constituye un tratado, se trata de una resolución de la Asamblea General de Naciones Unidas, que recoge principios propios del derecho internacional consuetudinario y viene a ampliar normas contenidas en diversos tratados. Cfr. Informe del ex Relator Especial sobre Pueblos Indígenas, James Anaya, sobre Derechos de los Pueblos Indígenas A/68/317, 14 de agosto de 2013. En línea, disponible en: http://www.politicaspublicas.net/panel/ images/stories/docs/2013-ga-annual-report-sp.pdf

13 Énfasis añadido.

14 La misma conclusión se deriva para el proceso penal de la consideración del artículo 342 letra d) del Código Procesal Penal, toda vez que las razones legales o doctrinales que sirven para calificar un hecho, circunstancia o fundar el fallo, constituyen un contenido de la sentencia cuya omisión acarrea su nulidad. 
su derecho a la libre determinación (artículos 8.2 y 9.1). También, el Convenio 169 de la OIT contiene normas referidas a la aplicación de penas alternativas ${ }^{15}$ a la privación de libertad y la prohibición del trabajo forzado (artículos 10 y 11). Por último, y no menos importante, el reconocimiento de la diversidad implica el derecho de los indígenas para acceder a la justicia estatal (artículo 12). La tercera dimensión de los derechos indígenas ante la justicia, es decir, el derecho a las penas alternativas y pertinentes, no son materia de este análisis, por lo que me centraré en los otros tres aspectos.

\subsection{Derecho al reconocimiento del derecho propio por el Estado y respuestas de la justicia estatal al pluralismo legal}

En relación con el primer punto, es necesario distinguir el reconocimiento que la justicia del Estado hace del derecho indígena, de la preocupación que, desde antiguo, tiene el derecho penal liberal por hacer un reproche diferente a quien no forma parte de la cultura que hace el juicio de reproche. En efecto, de cara al problema de la contradicción de una norma de derecho estatal, en cuanto expresión

\footnotetext{
Si bien se ha sostenido que las normas relativas a las sanciones penales obligan al juez a aplicar la pena "más baja que el sistema jurídico admita" (Meza-Lopehandia 2013: 419), diferimos de tal afirmación. La norma de determinación de pena que contempla el Convenio 169 de la OIT se refiere no al quantum de la pena, sino a su naturaleza. En este sentido, el juez está obligado, en primer término, a preferir sanciones no privativas de libertad, lo que implicaría que el juez (sin perjuicio de la obligación del legislador de establecer penas alternativas especiales) debe ponderar, especialmente, la calidad indígena del condenado, junto a otras posibles (al modo como se aplican las reglas de determinación de pena para adolescentes), y a considerar las condiciones particulares del condenado (principios que, en otro sentido, ha aplicado la Corte Interamericana de Derechos Humanos).
}

de la cultura hegemónica, con otra proveniente de la cultura minoritaria, se intenta encontrar soluciones alternativas y excepcionales. Es lo que en la doctrina europea y norteamericana se denomina cultural defenses (Carnevali 2007).

La dogmática penal ha dado distintas respuestas al dilema que se produce cada vez que el Estado formula una imputación penal a quien pertenece a una cultura diferente. Por ejemplo, para las teorías de la conducta socialmente adecuada, este dilema se resuelve por la falta de tipicidad (García 2003). También a nivel de tipicidad, se encuentra el error de tipo culturalmente condicionado ${ }^{16}$ : "[e]ste error dice relación con la dificultad o impedimento que tiene el sujeto para reconocer los elementos constitutivos del tipo penal, en razón de sus cuestionamientos culturales" (Villegas 2012: 199).

En cambio, para otros:

[E]n el caso del enfermo mental, del indio, del menor, del sordomudo, el problema va más allá de la simple inimputabilidad y abarca todo el delito. Se trata de que en estos casos, en mayor o menor grado, hay una distinta racionalidad, en distinto orden de cosas en los que se mueven estos sujetos y que informan todos sus actos (Bustos 2007: 341).

Zaffaroni, por su parte, explica que estas acciones podrían explicarse, según el caso, como error de comprensión o "error culturalmente condicionado" (1988: 585). En efecto, se incurre en error de prohibición en aquellos casos en que "producto de un proceso de socialización exótica el autor actúa afectado por lo que denomina conciencia disidente que hace que el autor crea falsamente que

16 Tratado en profundidad en Defensoría Penal Pública (2012a). 
existe una causa de justificación legal que le dispensa de su obligación o que se encuentra en una situación de justificación que no existe" (Barrientos 2008: 7). Al respecto, es necesario tener presente que "no se trata de un desconocimiento de la prohibición (ni total ni parcial), sino de la ausencia de internalización de la misma por parte del sujeto, por su pertenencia a una cultura distinta" (Villegas 2012: 196).

Se pueden distinguir, en suma, cuatro tipos de error:

a) si se debe a desconocimiento total o parcial de la norma penal o de sus reformas, o b) que el sujeto no comprende lo injusto de su actuar, no por desconocimiento de la norma, sino porque está obedeciendo a otra conciencia que lo determina en su actuar, o c) que el sujeto cree estar amparado por una causal de justificación que en realidad no lo ampara, o d) que el sujeto desconoce o no comprende alguno de los elementos del tipo penal (Villegas 2012: 202).

En el caso de que una conducta ilícita se considere como ejercicio legítimo de un derecho, el elemento de punibilidad que no concurre es la antijuricidad. La conducta está descrita como delito, pero a la vez constituye el ejercicio de un derecho para su autor indígena.

Todos estos casos tienen algo en común. Se trata de respuestas que se formulan dentro del mismo sistema jurídico, considerando la diferencia cultural que está detrás del actuar punible, como una variable de la conciencia de antijuridicidad de la conducta disruptiva del otro, o simplemente como un error.

106 El punto que nos interesa, en cambio, es cómo el derecho estatal considera en su praxis la diversidad cultural y el reconocimiento del otro en tanto colectivo, en tanto titular de una forma de pensamiento y conocimiento, de un derecho diferente o derecho propio. Este último concepto "es relativo de manera directa al hecho de que los indígenas tienen sus propias filosofías jurídicas, sus privativos órdenes normativos, sus adecuadas instituciones $y$ sus pertinentes jueces, y que, en tal orden, dichas instituciones y jueces son diferentes, competentes, independientes y autónomos en sus procedimientos y decisiones" (Martínez, Steiner y Uribe 2012: 56).

En este sentido, durante la vigencia del sistema acusatorio, los tribunales han debido enfrentarse a esta realidad, reaccionando desde distintas miradas, sea desde el desconocimiento o la asimilación, el indigenismo o el reconocimiento de la diversidad. Aunque no se aprecia una línea evolutiva progresiva, se han producido avances y retrocesos.

En el área del reconocimiento del derecho propio, los tribunales -especialmente al apreciar las cultural defenses- dejan traslucir cuál es el tipo de reconocimiento hacia el derecho diferente. No obstante, las respuestas a las cultural defenses siempre son respuestas desde el derecho del Estado, y por eso, en general, se perciben más cercanas a las respuestas que desconocen el pluralismo jurídico. Bajo el principio del reconocimiento de la diversidad cultural:

[E]l Estado tiene la especial misión de garantizar que todas las formas de ver el mundo puedan coexistir pacíficamente, labor que no deja de ser conflictiva, pues estas concepciones muchas veces son antagónicas e incluso incompatibles con los presupuestos que él mismo ha elegido para garantizar la convivencia. En especial, son 
claras las tensiones entre reconocimiento de grupos culturales con tradiciones, prácticas y ordenamientos jurídicos diversos y la consagración de derechos fundamentales con pretendida validez universal (Sentencia de la Corte Constitucional de Colombia recaída en la Tutela T- 523 de 1996) ${ }^{17}$.

\subsection{Consideración de la diversidad por tribunales penales}

En cambio, entre nosotros abundan, precisamente, aquellas posiciones que niegan la posibilidad de un actuar diferente bajo parámetros culturales diversos. Los tribunales deslegitiman esta propuesta, con fundamentos como el siguiente:

[S]e pretendió acreditar que el sentenciado obró impulsado por una fuerza irresistible (...) al ver que su cuñada...estaba intimando con el ofendido, lo que a su vez dentro de la cultura mapuche, de la que es integrante, lo habría impulsado a actuar en defensa del honor de toda su familia que era la que en definitiva resultaba afectada por esta situación (...) Que si bien es cierto la situación antes descrita pudo haber ofuscado al acusado, ella no justifica que haya agredido a la víctima hasta el punto de quitarle la vida (TOP Temuco, RIT 045-2008, 18 de abril de 2008).

El rol de vínculo o nexo que la antropología puede hacer en este punto, parece aún no ser muy relevante. La antropología jurídica "ha configurado un marco teórico-conceptual y metodológico que permite entender la impronta de la cultura en la configuración de

Desde las primeras sentencias (véase, además, T-349 de 1996), la Corte Constitucional de Colombia postuló como mecanismo para resolver estos dilemas el establecer un verdadero "consenso intercultural". Asimismo, diseñó las reglas de "maximización de la autonomía de las comunidades indígenas" y "minimización de las restricciones indispensables para salvaguardar intereses de superior jerarquía", principios que han sido revisitados constantemente durante estas décadas. los sistemas normativos" (Sánchez y Gómez 2008: 7), de modo que se podría constituir en un instrumento que favorezca la aplicación del principio de la diversidad por parte de los jueces, y ayudarlos a ver lo que no ven.

En esta dirección, es necesario comprender que, en un mismo espacio geográfico, pueden coexistir diversos sistemas normativos $y$ culturales, y que los primeros se encuentran influidos de forma determinante por los segundos. Asimismo, es importante atender que cuando nos referimos al derecho indígena, no hablamos exclusivamente de prácticas ancestrales desaparecidas en el tiempo, de las que sólo pueden dar cuenta los cronistas del período prehispánico.

A su vez, el apoyo de la antropología en este tipo de procesos no sólo permite "pronunciarse específicamente acerca de si la conducta del imputado responde a alguna costumbre" (Bertini y Yáñez 2013: 156), sino que también permite entender el contexto sociocultural en que se produce un hecho determinado. Todas las hipótesis legales que determinan o no la aplicación de un castigo se deben entender en el espacio sociocultural en el que el hecho ocurre, y remitir a preguntas tales como: ¿cuándo existe un derecho legítimo que ejercer?, ¿cuándo hay fuerza irresistible?, y hasta ¿qué se entiende por familia o lazos familiares?

Precisamente, esto fue lo que ocurrió en el caso de parricidio por omisión seguido en contra de una mujer aymara. A ella se le eximió de responsabilidad, "por cuanto no podía actuar como garante de los derechos del hijo menor, pues su realidad familiar responde a una organización patriarcal que subsiste en la zona altiplánica otorgando poderes 
incontrarrestables al hombre" (Bertini y Yáñez 2013: 157) ${ }^{18}$.

Los jueces han replicado para el peritaje antropológico las exigencias previstas para cualquier otro medio probatorio. Esto es así aun cuando el valor otorgado al peritaje antropológico no es el mismo que se le entrega a otros peritajes sobre conocimientos científicos, llegando incluso a rechazarlos "pues 'la antropología no es una ciencia exacta' y por tanto no se ajusta a ninguno de los parámetros exigidos a una prueba judicial para producir certeza judicial" (Castro et al. 2009: 75).

Comparado con los avances producidos en otros Estados ${ }^{19}$, el panorama no parece ser muy favorable. Sin embargo, en el curso de la década se pueden apreciar algunos avances ${ }^{20}$. Se han ido entregando otro tipo de respuestas, casi siempre recurriendo al denominado error culturalmente condicionado ${ }^{21}$.

18 En todo caso, es necesario aclarar que en el fallo referido (Sentencia de la Corte de Apelaciones de Antofagasta, 9 de noviembre de 2006, en causa Rol $N^{\circ}$ 168-2006), se anuló la sentencia condenatoria y se dictó una absolutoria de reemplazo, en razón de que la resolución incurrió en un error de derecho. Dicho error se provocó no sólo porque la imputada no podía estar en posición de garante según lo razonado en los motivos precedentes (aspectos culturales señalados pero también dogmáticos, ya que de acuerdo a la doctrina citada en el fallo no existe el parricidio por omisión), sino básicamente porque ninguno de los hechos establecidos por los jueces de fondo se vinculaban o relacionaban causalmente con las lesiones o la muerte del menor, sea por acción, en la medida en que no se determinó la actividad realizada por la imputada KWGM, idóneas y demostrativas que justifiquen dicha muerte o lesiones, sean actos omisivos, cuya consecuencia haya generado el mismo resultado (Considerando $1^{\circ}$ ).

19 Al respecto, ver en profundidad Villegas (2012).

20 Diferimos con Bertini y Yañez (2013), para quienes la práctica judicial ha negado -en materia penal- valor legal al contexto sociocultural.

Un análisis acabado de jurisprudencia en materia indígena se encuentra en Castro et al. (2009).
Éste es el caso de una sentencia de $2004^{22}$, en la que los jueces decidieron que el acusado no había cometido desacato, no obstante haber reingresado al terreno del que había sido anteriormente desalojado judicialmente. Su fallo se fundó en que no concurría en el imputado el elemento de la culpabilidad, porque el acusado incurrió en un error de prohibición, "esto es, actuó creyendo equivocadamente, por error inevitable, que se encontraba amparado en la casual de justificación del artículo $10 \mathrm{~N}^{\circ} 10$ del Código Penal, por ejercicio legítimo de un derecho, lo que obsta a la conciencia de la ilicitud de su conducta" (Sentencia RIT 041/2004, Considerando $9^{\circ}$ ). El tribunal adquirió la convicción de que el inculpado actuaba en todo momento como señor y dueño de la propiedad, teniendo dos sustentos jurídicos para ello. Por un lado, el hecho de que los antepasados del imputado habían sido efectivamente los dueños de la propiedad ${ }^{23}$, y por otro, considerando el valor que los indígenas otorgan a su tierra, valiéndose para ello de un informe antropológico evacuado por funcionarios de la Corporación Nacional de Desarrollo Indígena.

Este mismo criterio llevó a los ministros de la Corte de Apelaciones de Valdivia a absolver a dos personas mapuche huilliche acusadas $-\mathrm{y}$ condenadas en primera instancia- por el delito de usurpación. Esto se explica porque, si bien habían ocupado un predio de Fernando Léniz Cerda en la comuna de Panguipulli, no tenían el ánimo de señor o dueño, pues ésta es la forma tradicional en que los mapuche han reivindicado

22 Sentencia definitiva, 11 de junio de 2004, dictada por los jueces del TOP de Temuco Ester Valencia Durán, Cristian Alfaro Muirhead y Jorge González Salazar, en causa RIT 041/2004.

23 Inclusive había obtenido la posesión efectiva, la que inscribió en el Conservador de Bienes Raíces de Temuco, y contaba con testigos que declararon en este mismo sentido. 
sus derechos territoriales (Sentencia definitiva de la Corte de Apelaciones de Valdivia, 14 de noviembre de 2001, en causa Rol No 110.077-01).

En casos similares en los que existe una reivindicación territorial, $o$ de recursos naturales, es posible invocar, además, la noción de tierra y territorio que establece el artículo 13 del Convenio 169 de la OIT $^{24}$. La Corte Interamericana de Derechos Humanos ha ido desarrollando dicha noción en su jurisprudencia desde el caso de Awas Tingni hasta Sarayaku²5, según la cual "[p]ara las comunidades indígenas la relación con la tierra no es meramente una cuestión de posesión y producción sino un elemento material y espiritual del que deben gozar plenamente, inclusive para preservar su legado cultural y transmitirlo a las generaciones futuras" (Comunidad Mayagna Awas Tingni v/s Nicaragua, párr. 149).

En esta línea, se puede citar como un pronunciamiento -que se aproxima aún más a la consideración de la diversidad- la sentencia del TOP de Calama y confirmada por la Corte de Antofagasta, la cual absuelve a dos mujeres quechuas sorprendidas portando hojas de coca:

Entonces, lo que estos sentenciadores entienden, y de ahí su convicción absolutoria, es que las acusadas, no obstante realizar una conducta

24 Artículo 13.1. Al aplicar las disposiciones de esta parte del Convenio, los gobiernos deberán respetar la importancia especial que para las culturas y valores espirituales de los pueblos interesados reviste su relación con las tierras o territorios, o con ambos, según los casos, que ocupan o utilizan de alguna otra manera, y en particular los aspectos colectivos de esa relación. Artículo 13.2. La utilización del término "tierras" en los artículos 15 y 16 deberá incluir el concepto de territorios, lo que cubre la totalidad del hábitat de las regiones que los pueblos interesados ocupan o utilizan de alguna otra manera.

25 Entre otras sentencias de la Corte, Comunidad Mayagna de Awas Tngni v/s Nicaragua de 2001, y comunidad Kichwa de Sarayaku v/s Ecuador de 2012. reprochable, lo hicieron siguiendo las formas y simbolismos propias de su cultura, lo que significa que ellas, en su conciencia y fuero interno, no tuvieron la intención de traficar las hojas de coca, sino entregárselas a una persona que, como creyente, las iba a utilizar en una festividad religiosa (TOP Calama RIT 66-2010, 6 de octubre de 2007).

Aun cuando la decisión absolutoria se funda en que las acusadas habrían cometido un "error" al considerar que la conducta no era prohibida, existe una consideración diferente del otro, pues, implícitamente, se encuentra el reconocimiento de una juridicidad distinta. Incluso, en la mera identificación de la otredad, ahora a secas, sin (o con menos) calificaciones, es posible desprender:

\begin{abstract}
Que todos los comuneros mapuches conviven en un mismo sector y se autodefinen, dentro de la comunidad tradicional, con la expresión Wente Winkul Mapu y, por consecuencia, conservan la plena identidad de ese pueblo autóctono y tradicional al que debe reconocerse y respetarse sus arraigadas costumbres, en especial con relación a su pertenencia racial y territorial (Sentencia de la Corte Suprema, 20 de julio de 2012, en causa Rol $\mathrm{N}^{\circ}$ 5441-2012).
\end{abstract}

Con todo, es necesario insistir en que, en el caso de estos argumentos que permiten eximir de responsabilidad penal, o atenuarla, éstos se fundan en las consideraciones del propio derecho penal estatal. En efecto, se evalúa la conducta del individuo siempre desde la perspectiva del orden jurídico estatal, y se le exime o atenúa el reproche porque su actuar se encuentra influido por su cultura, sea porque se vio forzado a actuar de ese modo, por sus patrones culturales, o sencillamente porque no creyó que sus acciones fueran contrarias a la ley (Couso 2013). Esto quiere decir que el sistema penal resulta permeable a la pluriculturalidad en relación con la situación 
subjetiva del imputado, aunque, no obstante, es reticente a la consideración colectiva de un derecho distinto, que ampare, por tanto, su forma de actuar aunque esté penado por ley del Estado.

\subsection{Jurisdicción especial indígena}

En materia de reconocimiento a la jurisdicción indígena, los pasos son aún muy tímidos. Esto se demuestra en los dichos de la Corte de Concepción, a propósito de un recurso de nulidad intentado por la defensa pública, en que se alegaba que el asunto ya había sido resuelto por la comunidad bajo los principios del derecho propio:

Una sentencia dictada por la comunidad a la que pertenece el imputado o una sanción penal impuesta por ellos, no es compatible con nuestro sistema jurídico nacional, de manera que no tiene aplicación el artículo $9^{\circ}$ antes transcrito. En efecto, el artículo 76 de la Constitución Política de la República dispone que: "La facultad de conocer las causas civiles y criminales, de resolverlas y de hacer ejecutar lo juzgado, pertenece exclusivamente a los tribunales establecidos por la ley". El artículo $19^{\circ}$ de la Carta Fundamental, en su numeral $3^{\circ}$, al establecer la garantía de la igual protección de la ley en el ejercicio de sus derechos, expresa, en su inciso $7^{\circ}$, que: "Nadie puede ser juzgado por comisiones especiales, sino por el tribunal que le señale la ley y que se halle establecido con anterioridad por ésta", y agrega, en su inciso siguiente, que: "Toda sentencia de un órgano que ejerza jurisdicción debe fundarse en un proceso previo, legalmente tramitado" (Corte de Apelaciones de Concepción, 2 de mayo de 2014, en causa Rol N 195-2014).

Aquí no hay juzgamiento por comisiones especiales, entendidas "como tribunales ad hoc, creados para juzgar un caso concreto o a una determinada persona o grupo de personas en particular, sin que se garantice la imparcialidad e independencia del juzgador, vulnerando el principio de igualdad conforme al cual todos los ciudadanos en idénticas situaciones deben ser juzgados por el mismo tribunal" (Lübert 2011: 93-94), sino todo lo contrario. En efecto, se trata de autoridades y formas que los indígenas ${ }^{26}$ utilizan para reprimir los delitos y resolver los conflictos jurídicos al interior de sus comunidades, siguiendo los términos del Convenio 169 de la OIT.

Si la prohibición de las comisiones especiales tiene que ver con que aquél que sea sometido a un juicio penal no se encuentre ante la imposibilidad de prever quién lo juzgará y bajo qué procedimiento, y que, en cambio, se vea enfrentado ante un tribunal del que no puede garantizarse su imparcialidad, las decisiones jurisdiccionales de una comunidad indígena revisten características totalmente opuestas ${ }^{27}$, que constituyen, en suma, lo que nosotros llamamos el juez natural. Si el reconocimiento de jurisdicción aún es un desafío por perseguir, la brecha del monismo jurídico se ha fracturado ahí, donde la diversidad ha podido filtrarse.

En materia de reconocimiento de la justicia indígena, es decir, de aquellos casos en que la justicia estatal se abstiene de actuar porque ya lo habría hecho la indígena, un caso paradigmático lo constituye la aceptación de acuerdos reparatorios en casos de violencia intrafamiliar entre indígenas. En la ley sobre violencia intrafamiliar de Chile, no es posible llegar a esta salida alternativa, porque se entiende que la víctima de violencia doméstica

26 En este caso mapuche.

7 Toda vez que se pueda demostrar que existen instituciones propias, utilizadas en el tiempo, reconocidas en la comunidad y analizadas, por ejemplo, bajo los principios de la jurisprudencia de la Corte Constitucional de Colombia. 
presenta un grado de sumisión que le impide denunciar. Sin embargo, los tribunales inclusive la Corte Suprema ${ }^{28}$ - han entendido que en estos casos sí puede aceptarse un acuerdo entre indígenas, en el entendido de que aquello conforma una forma tradicional de resolver conflictos al interior de la comunidad ${ }^{29}$. Algo similar se replica en casos como el de la comunidad de Socaire ${ }^{30}$, en que un conflicto interno se resuelve mediante un acuerdo reparatorio, el que, más bien ${ }^{31}$, formaliza un acuerdo ya asumido al interior de la comunidad.

En este sentido, el uso de la justicia tradicional puede convertirse en un buen mecanismo de despenalización. Estos casos demuestran cómo en este espacio del derecho oficial las fuerzas en conflicto no permanecen estáticas, sino que, al contrario, su relación es más bien compleja, pues en él conviven los mandatos formales del Convenio, pero también la forma de aplicarla de los actores del sistema, de los movimientos indígenas, y con los aportes de las ciencias sociales.

\subsection{Derecho al acceso a la justicia estatal}

La cuarta dimensión de los derechos reconocidos en el Convenio 169 de la OIT se refiere a los

28 Que ha rechazado, al menos en dos ocasiones (en causas Ro $\mathrm{N}^{\circ} 10635-2011$ y $\mathrm{N}^{\circ}$ 592-2012), las quejas interpuestas por el Ministerio Público en contra de las resoluciones que dan lugar a los acuerdos reparatorios.

29 Aunque estos casos han sido rodeados de una polémica, aquello no tiene que ver con el reconocimiento del derecho indígena, sino con la eventual colisión de derechos, cuestión que corresponde a un paso posterior (Defensoría Penal Pública 2012b; Lillo 2010).

30 Juzgado de Garantía de Calama, 29 noviembre de 2013, RIT 4657-2012

31 La audiencia en la que se aprobó el acuerdo reparatorio se realizó en el pueblo de Socaire con asistencia de autoridades e integrantes de la comunidad. derechos ante la justicia. Como ya lo considera este Convenio y lo reitera la DNUDPI ${ }^{32}$, el reconocimiento de estos derechos especiales no implica desconocer o menoscabar los derechos individuales, reconocidos en instrumentos generales como los pactos de derechos. En este sentido, los pueblos indígenas y sus integrantes tienen, por una parte, derecho a su jurisdicción especial, y por otra, derecho al acceso a la justicia estatal sin discriminación.

Por un lado, el ejercicio de este derecho involucra no sólo el acceso a un intérprete, sino que también se debe garantizar que los indígenas puedan comprender adecuadamente lo que ocurre en un proceso, facilitando para ellos cualquier mecanismo eficaz ${ }^{33}$. En el caso del poder judicial, se pueden considerar avances notables como la constitución de salas especiales, o bloques especiales de audiencias para casos indígenas en los Juzgados de Garantía de Temuco en la región de La Araucanía $^{34}$. Si bien, esto no se traduce en una especialización de los jueces, podría constituir una base para aquello, y permite desde ya que se conforme como una cuestión relevante entre los asuntos que deben resolver.

Por otro lado, recientemente ${ }^{35}$ se ha dado a conocer el "Protocolo Iberoamericano de Actuación Judicial para mejorar el acceso a la justicia de personas con discapacidad, migrantes, niñas, niños, adolescentes, comunidades y pueblos indígenas". Este instrumento

\footnotetext{
Artículo 37.2 del DNUDPI.

33 Artículo 12 del Convenio 169 de la OIT.

34 Ver http://www.dpp.cl/sala_prensa/noticias_detalle/5547/ defensoria-de-la-araucania-impulsa-sala-especializada-paraaudiencias-mapuche-en-temuco

35 Como producto de la XVII Cumbre Judicial Iberoamericana, 2-4 de abril de 2014, Guadalajara, México.
} 
pretende dar continuidad a las Reglas de Brasilia, estableciendo estándares que hagan aplicable las normas previstas en tratados internacionales de Derechos Humanos.

El apartado sobre personas y comunidades indígenas "busca auxiliar a las y los juzgadores en su tarea de impartir justicia de forma especializada, acercándoles los estándares internacionales y algunos ejemplos de buenas prácticas y resoluciones de diversos países de Latinoamérica"36. El Protocolo, basándose en lo establecido por la DNUDPI, el Convenio 169 de la OIT y los Pactos de Derechos civiles, políticos, económicos, sociales y culturales, describe algunos principios para que sean aplicados por los jueces en su labor habitual: el principio de igualdad y no discriminación según la Corte Interamericana de Derechos Humanos; el principio de maximización de la autonomía, acuñado por la Corte Constitucional de Colombia, y; el reconocimiento de la Jurisdicción Especial Indígena.

Este Protocolo podría llegar a conformarse en un instrumento significativo para el reconocimiento de la diversidad en la actuación de los tribunales. Si bien no constituye una norma vinculante para los jueces como una ley o reglamento, se trata de un instrumento oficial ${ }^{37}$ que interpreta tratados de Derechos Humanos, que sí son obligatorios para los jueces. En definitiva, es una guía para la aplicación del control de convencionalidad por parte de los jueces.

36 Protocolo Iberoamericano de actuación judicial para mejorar el acceso a la justicia de personas con discapacidad, migrantes, niñas, niños, adolescentes, comunidades y pueblos indígenas, Suprema Corte de Justicia de la Nación, México, D.F. En línea, disponible en: www.supremacorte.gob.mx

Se trata de un documento suscrito por una asociación que incluye a las cortes supremas de países iberoamericanos.
En este proceso, la Defensoría Penal Pública, a través de la Defensoría Penal Mapuche con oficinas en la Novena Región, ha jugado un rol positivo (Marensi 2007). En agosto de 2001, la Defensoría Penal Pública crea en la Región de La Araucanía una oficina especializada de Defensa Penal Mapuche, con dos abogados especializados y un facilitador intercultural ${ }^{38}$.

Con la ratificación del Convenio 169 en septiembre del 2008, la Defensoría Penal Pública comenzó a trabajar en la elaboración de un Modelo de Defensa Penal Indígena, que permitiera a la institución prestar defensa de calidad a imputados pertenecientes a los pueblos originarios. En el año 2012 se implementa el Modelo de Defensa Penal para imputados indígenas, permitiendoa lainstitución otorgar defensa penal a través de abogados especializados en materias indígenas, que hayan sido capacitados en materias relativas a interculturalidad, Convenio $\mathrm{N}^{\circ} 169$ de la OIT, nociones de Derecho Internacional de los Derechos Humanos, Derecho Constitucional, Derecho Penal con enfoque en la diversidad cultural de los pueblos originarios, etc.

Esta preparación se ha llevado adelante a través de las Academias de Defensa Penal para Imputados Indígenas, actividad anual que se realiza para formar nuevos defensores especializadosy para perfeccionar y profundizar conocimientos de defensores que cuentan ya con la especialidad. Esto ha permitido que en la institución existan al día de hoy más de 200 profesionales capacitados en la materia, de los cuales 174 son defensores públicos.

\footnotetext{
Actualmente la Defensoría Penal Mapuche cuenta con tres defensores especializados, dos facilitadores y una asistente administrativa.
} 
Paralelamente, la Defensoría Penal Pública cuenta con un equipo de 7 facilitadores interculturales, que son los encargados de colaborar en la prestación de defensa, llegando a realizar tareas como intérprete/traductor, facilitar la comprensión de la cultura del imputado por parte de defensores y jueces (tradiciones, creencias, costumbres, etc.), y realizar difusión de derechos al interior de las comunidades, entre otros. Los facilitadores están dispuestos estratégicamente en algunas de las zonas geográficas con mayor presencia de población originaria (Arica, Iquique, Calama, Cañete y Temuco), y su ámbito de trabajo es regional. Para ellos se realiza también un taller de capacitación de carácter anual. Por último, se ha desarrollado institucionalmente una herramienta informática para el registro de las causas con imputados indígenas, que tiene por finalidad obtener más y mejores datos que permitan tomar decisiones institucionales con información de calidad.

Durante el año 2013, la Defensoría asistió a 6.216 imputados indígenas, lo que representa el 1,8\% del total de personas a las que se ha prestado defensa pública en el país. El 35,1\% de estos imputados es de la Región de La Araucanía, el 11,8\% de Tarapacá, y el 10,9\% de Arica y Parinacota, ratificando que estos imputados provienen prioritariamente de los territorios tradicionalmente ocupados por los pueblos indígenas en Chile (Defensoría Penal Pública 2014).

En suma, el enfoque de la defensa especial indígena ha permitido poner en debate el uso del derecho tradicional indígena. A su vez, a través de sus defensas, ha colaborado a generar procedimientos de atención de público y uso de peritajes antropológicos en los juicios que den cuenta de este otro derecho.

\section{A modo de conclusión}

Si el derecho es un escenario de lucha y conflicto, el sistema penal es un campo fructífero de aquello. En el proceso de desarrollo del contexto que constituye el nuevo sistema procesal penal, las conflictividades presentes entre los distintos derechos que conviven en él se pueden expresar de distintas maneras. Formalmente, los tribunales estatales se manifiestan a través de sus sentencias (aunque el derecho vive más allá de ellas). En ellas se aprecia un avance en el reconocimiento de la diversidad, el que no es posible entender sin las contribuciones que la antropología jurídica puede ofrecerle al derecho.

El propio concepto de pluralismo jurídico al que me he referido, no es sino parte del origen mismo de la antropología. Más tarde, la idea de interlegalidad y de campos semi-autónomos son todos aportes que permiten a la dogmática entender fenómenos sobre los cuales nunca ha puesto demasiada preocupación. Lo mismo ocurre con la idea de "territorio" o "pueblo", la cual ha permitido comprender que las demandas de los movimientos son mucho más que delitos y expresiones anti-sistémicas, en un espacio que presume ser cerrado y completo.

En definitiva, la idea del "derecho propio", sobre el que tantas veces volviera nuestra compañera María del Rosario Salamanca (s/f), forma parte de aquellos avances de la antropología que permiten ver tanto la realidad como el sistema de justicia que persiste en mirarse a sí mismo para buscar sus respuestas. Si ya no es posible entender el derecho como un espejo del Estado, el ejercicio del mismo no puede sino ser un ejercicio interdisciplinario e interétnico, dando pie a un escenario de lucha más equitativo y más democrático. 


\section{Bibliografía}

Baratta, A. 1986. Criminología crítica y crítica al derecho penal. México D.F.: Siglo XXI Editores.

Barrientos, I. 2008. "Licitud del porte y uso de la hoja de coca". Revista Política Criminal 5: 1-30. En línea, disponible en: http://www.politicacriminal.cl/n_05/A_4_5. pdf (visitado el 10 de diciembre de 2014).

Bertini, L. y Yáñez, N. 2013. "Pluralismo jurídico: Derecho indígena y justicia nacional". Anuario de Derechos Humanos 9: 151-160.

Bustos, J. 2007. Obras completas. Tomo II. Control social y otros cambios. Santiago: Ediciones Jurídicas de Santiago.

Carnevali, R. 2007. "El multiculturalismo. Un desafío para el derecho penal moderno". Revista Política Criminal 3:1-28. En línea, disponible en: http://www.politicacriminal. cl/n_03/a_6_3.pdf (visitado el 10 de diciembre de 2014).

Castro, M. et al. 2009. Jurisprudencia indígena. Cosmovisión y legislación. Santiago: PRANJU.

Couso, J. 2013. "Mapuches y derecho penal". Derecho y pueblo mapuche. Olea, H. (Ed.). Santiago: Diego Portales. 155-214.

Defensoría Penal Pública. 2014. Estudio evaluativo de estadísticas del Programa de Defensa Penal Indígena. Santiago: DPP.

2012a. Defensa de adolescentes indígenas: Propuestas para tener presente, discutir y profundizar. En línea, disponible en: http://www.biblio.dpp.cl/biblio/ DataBank/6960.pdf (visitado el 10 de diciembre de 2014). 2012b. Comentarios a fallos relevantes en materia de defensa penal de imputados de pueblos originarios. Algunos aspectos para la mejor aplicación del Modelo de Defensa Penal. En línea, disponible en: http:// www.biblio.dpp.cl/biblio/DataBank/6367.pdf (visitado el 10 de diciembre de 2014).

Diez, J. L. 2007. La política criminal en la encrucijada. Montevideo-Buenos Aires: Editorial B de F.

Jiménez, M. A., Santos, T. y Medina, P. 2012. "Reorientaciones de la justicia penal a 12 años de la Reforma Procesal Penal". Revista Nova Criminis 4: 161-325.

Hassemer, W. 1998. Crítica al derecho penal de hoy. Bogotá: Universidad Externado de Colombia.

García, E. 2005. "Culturas diversas y sistema penal". Derecho Penal. Memoria del Congreso Internacional de Culturas y Sistemas Jurídicos Comparados. García, S. (Ed.). México D. F.: Universidad Nacional Autónoma de México. 117-177.

Garland, D. 1999. La cultura del control. México D.F.:
Siglo XXI Editores.

Guevara, A. 2001. "Las causas estructurales de la pluralidad legal en el Perú". Revista Derecho \& Sociedad II (VXI): 325-340.

González, K., Mella, E. y Lillo, R. 2007. "La política de criminalización del movimiento mapuche bajo el sexenio de Lagos". El gobierno de Lagos, los pueblos indígenas y el "nuevo trato". Yáñez, N. y Aylwin, J. (Eds.). Santiago: LOM. 59-99.

Lillo, R. 2010. El Convenio 169 de la OIT y la defensa penal de indígenas. En línea, disponible en: http://www. dpp.cl/resources/upload/093e523d3fa9fe3d8745793ada 63a58b.pdf (visitado el 10 de marzo de 2015).

2002. "Pluralismo jurídico en Chile. Un desafío pendiente". III Encuentro y Simposio Internacional de la Red Latinoamericana de Antropología Jurídica. Pluralismo jurídico: Presente y futuro. Quetzaltenango, Guatemala. 2001. "Los derechos de los indígenas y el nuevo sistema procesal penal". Revista de la Escuela de Derecho de la Universidad Católica de Temuco 2: 87-136.

Lübert, V. 2011. "El derecho a no ser juzgado por comisiones especiales: Análisis crítico de jurisprudencia". Revista de Estudios de la Justicia 15: 87-107.

Marensi, I. 2007. "Reforma procesal penal y pueblos indígenas". Revista Sistemas Judiciales 6 (12): 42-59.

Martínez, J. C., Steiner, C. y Uribe, P. (Coords.). 2012. Elementos y técnicas de pluralismo jurídico. Manual para operadores de justicia. México D.F.: Fundación Konrad Adenauer.

Mella, E. 2007. Los mapuche ante la justicia. La criminalización de la protesta indígena en Chile. Santiago: LOM.

Mera, J. y Duce, M. 1996. Introducción al sistema penal. Santiago: Ediciones Universidad Diego Portales.

Meza-Lopehandia, M. 2013. "El Convenio N 169 sobre pueblos indígenas y tribales de la Organización Internacional del Trabajo". Los pueblos indígenas y el derecho. Aylwin, J. (Coord.). Santiago: LOM. 337-440.

Pairican, F. 2014. Malón. La rebelión del movimiento mapuche. 1990-2013. Santiago: Editorial Pehuén.

Salamanca, M. (s/f). El derecho en la sociedad mapuche. Un análisis de acuerdo a los estudios publicados previos. En línea, disponible en: http://200.10.23.169/ trabajados/rosario.pdf (visitado el 18 de marzo 2015).

Sánchez, E. y Gómez, H. 2008. El peritaje antropológico como prueba judicial. Bogotá: Instituto Colombiano de Antropología e Historia. 
Sieder, R. 2002. "Pluralismo legal y globalización jurídica: Retos del multiculturalismo en América Latina". III Encuentro y Simposio Internacional de la Red Latinoamericana de Antropología Jurídica. Pluralismo jurídico: Presente y futuro. Quetzaltenango, Guatemala. LOM.

Stippel, J. 2013. Cárcel, derecho y política. Santiago:

Villegas, M. 2012. “Entre la exculpación y la justificación. Apuntes de legislación comparada latinoamericana sobre pluralismo jurídico y derecho penal". Revista de Derecho de la Facultad de Ciencias Jurídicas y Sociales de la Universidad Austral de Chile 25 (2): 177-205.

2007. El derecho penal del enemigo y la criminalización del Pueblo Mapuche. En línea, disponible en: https://tallerdememoria.wordpress.com/2007/08/21/ el-derecho-penal-del-enemigo-y-la-criminalizacion-delpueblo-mapuche-por-myrna-villegas-d/ (visitado el 10 de abril de 2015).

Young, J. 2003. La sociedad excluyente. Barcelona: Marcial Pons-Ediciones Jurídicas y Sociales.

Yrigoyen, R. 2000. "Reconocimiento constitucional del derecho indígena y la jurisdicción especial en los países andinos (Colombia, Perú, Bolivia, Ecuador)". Justicia penal y comunidades indígenas. Pena y Estado 4: 129-142.

Zaffaronni, E. 1988. Manual de derecho penal. México D.F.: Cárdenas Editor. 
